\title{
LA LIBERTAD DE EXPRESIÓN EN PROCESOS ELECTORALES. EL CASO DE LAS REDES SOCIALES
}

\author{
The freedom of expression in electoral process, specifically in social networks
}

\author{
Enoc Francisco MORÁN TORRES \\ Marco Antonio VALENCIA VILLATORO
}

La libertad de expresión, particularmente en asuntos de interés público, es una piedra angular en la existencia misma de una sociedad democrática”. Corte IDH.

Sumario:

I. Introducción. II. El derecho fundamental de la libertad de expresión. III. La Internet y las redes sociales. IV. La libertad de expresión en procesos electorales. V. Conclusiones.

Resumen: El presente trabajo de investigación se avoca al estudio del derecho fundamental de la libertad de expresión, analizado a partir de su naturaleza jurídica; de sus dimensiones individual y social o política; de sus posibles alcances, y de sus restricciones. De cómo varían los parámetros de protección del citado derecho fundamental dependiendo de la dimensión que se ejerza del mismo: individual o social; cuando dicho derecho se ejerce a través de La Internet y las redes sociales; $y$ cuando se ejerce bajo el contexto de los procesos electorales.

Asimismo, se analiza La Internet y las redes sociales, vistas como nuevas herramientas para el ejercicio de la libertad de expresión, su funcionamiento, sus características y sus diferencias con otros medios de comunicación.

Palabras clave: Derechos humanos. Democracia. Ciudadanos. Expresión. Ideas. Información. Internet. Libertad. Redes sociales.

Abstract: The present research paper intends to study the fundamental right to freedom of expression, analyzed from its legal nature, its individual and social or politic dimensions; its possible reach and its restrictions. Also, the variability of the parameters of protection of the given fundamental right depending on the dimension that its being exercised; from scenarios such as Internet and social networks to a context of electoral process.

Finally, Internet and social networks are analyzed as new tools for the exercising of the freedom of expression, along with their inner workings, their substantial characteristics and their differences with other forms of communication.

Key words: Human rights. Democracy. Citizens. Expression. Ideas. Information. Internet. Freedom. Social networks. 


\section{INTRODUCCIÓN}

El avance de la tecnología en muchas ocasiones ha rebasado al derecho, en virtud de que genera nuevas situaciones que no se encuentran reglamentadas o contempladas por los preceptos normativos, jurisprudenciales o doctrinales. En ese sentido, son los órganos jurisdiccionales, a través de sus juzgadores, los encargados de sujetar a derecho a esas nuevas realidades que imponen las nuevas tecnologías y la modernidad.

Una de esas nuevas realidades es el mundo de la Internet, específicamente en lo que respecta a las redes sociales, utilizadas como nuevas herramientas por los actores políticos y ciudadanos en general, para expresar sus ideas en el contexto del debate político y de los procesos electorales.

Sin embargo, la utilización de las redes sociales como espacios para la difusión de propaganda electoral y el desarrollo del debate político en los procesos electorales, carece de un escenario de regulación normativa en la legislación electoral mexicana vigente.

Lo anterior, a diferencia de algunos medios de comunicación, como la radio y la televisión, los cuales tienen un marco normativo a nivel constitucional, legal y reglamentario, así como también lo tienen la prensa escrita y algunos tipos de propaganda fija.

Así las cosas, los órganos jurisdiccionales electorales serán los encargados de sujetar a derecho a las redes sociales utilizadas en el desarrollo de los procesos electorales, cuando las expresiones y contenidos realizados en las mismas por los ciudadanos y actores políticos, en ejercicio de su derecho fundamental de expresión, entren en conflicto con los principios y valores democráticos que deben regir en los procesos electorales, así como con otros derechos fundamentales.

Para realizar lo anterior, es de suma importancia que las autoridades jurisdiccionales realicen un análisis de la naturaleza y alcance del derecho a la libertad de expresión; de las características de la Internet y las redes sociales, y del citado derecho a la libertad de expresión, ejercido bajo el contexto de la contienda electoral.

De ahí que, el propósito de la presente aportación académica es analizar, en esta que es la primera parte de una aportación académica más extensa, los alcances de la libertad de expresión en procesos electorales a través de las redes sociales a partir de la protección que, en el ámbito jurisdiccional, ha realizado el Poder Judicial de la Federación, particularmente el Tribunal Electoral. Mientras que en una posterior aportación, se realizará el análisis de la protección de la libertad de expresión en comento, a partir de diversos asuntos relevantes sometidos a la jurisdicción federal e interamericana.

\section{EL DERECHO FUNDAMENTAL DE LA LIBERTAD DE EXPRESIÓN}

La libre manifestación y flujo de información, ideas y opiniones, es una condición indispensable de prácticamente todas las demás formas de libertad, y como un prerrequisito para evitar el control del pensamiento, presupuesto esencial para garantizar la autonomía y autorrealización de la persona. ${ }^{1}$

El derecho fundamental de la libertad de expresión se encuentra consagrado en el artículo 6o. de la Constitución Política de los Estado Unidos Mexicanos, el cual establece en su texto normativo que la manifestación de las ideas no será objeto de inquisición judicial o admi-

\footnotetext{
${ }^{1}$ Véase. Tesis 1a. CDXX/2014 (1oa.), Semanario Judicial de la Federación, Décima Época, t. I, diciembre de 2014, p. 233.
} 
nistrativa, sino en el caso de ataque a la moral, la vida privada o los derechos de terceros, provoque algún delito o perturbe el orden público.

Asimismo, el arábigo 70. de la propia Norma Fundamental, declara inviolable la libertad de difundir opiniones, información e ideas por cualquier medio. Mientras que, los diversos 39 y 40 establecen que la forma de gobierno de México es democrática y representativa.

Además, los artículos 60., 70., 39 y 40 de la Carta Magna, guardan una relación sistemática innegable, pues juntos delinean una estructura jurídica apta para lograr el autogobierno democrático. Así, por un lado, los artículos 60. y 70. reconocen los derechos fundamentales de libertad de expresión y de acceso a la información, sin los cuales no sería posible una ciudadanía política y, por otro lado, los artículos 39 y 40 establecen que la forma de gobierno de nuestro país, es democrática y representativa.

En ese sentido, el derecho fundamental de libertad de expresión no sólo protege libertades necesarias para la autonomía personal de los individuos, sino también garantiza un espacio público de deliberación política. De modo que, mientras existan mejores condiciones para el ejercicio desinhibido de tal derecho, habrá mejores condiciones de ejercicio de los derechos políticos indispensables para el funcionamiento de la democracia representativa. ${ }^{2}$

De lo anterior, se observa que la libertad de expresión se presenta en dos dimensiones: la individual, que asegura a las personas espacios esenciales para desplegar su autonomía, autoexpresión y autorrealización individual; y la social o política, como pieza central para facilitar el funcionamiento adecuado de la democracia representativa y autogobierno. ${ }^{3}$

La libertad de expresión en su dimensión individual asegura a las personas espacios esenciales para desplegar su autonomía y libertad individual, esto es, existe un ámbito que no puede ser invadido por el Estado, en el cual el individuo puede manifestarse libremente sin ser cuestionado sobre el contenido de sus opiniones y los medios que ha elegido para difundirlas. Lo anterior aún y cuando el contenido del mensaje no sea necesariamente de interés público. ${ }^{4}$

Por otra parte, la libertad de expresión en su dimensión social o política es una pieza fundamental para el ejercicio de la democracia representativa, lo anterior en virtud de que la circulación de las ideas contribuye a generar una ciudadanía informada y al pluralismo político, valores esenciales del Estado democrático. ${ }^{5}$

De manera que esta dimensión del derecho fundamental en comento, cumple con las funciones siguientes: ${ }^{6}$

1. Mantener abiertos los canales para el disenso y el cambio político;

2. De contrapeso al ejercicio del poder, puesto que la opinión pública representa el escrutinio ciudadano de la labor pública;

2 Véase Tesis 1a. XXX/2016 (10a.), Semanario Judicial de la Federación, Décima Época, febrero de 2016, publicación semanal.

3 Véase Jurisprudencia P./J. 25/2007, Semanario Judicial de la Federación y su Gaceta, Novena Época, t. XXV, mayo de 2007 , p. 1520.

Véase Tesis 1a. CDXVIII/2014 (10a.), Gaceta del Semanario Judicial de la Federación, Décima Época, t. I, diciembre de 2014, p. 236.

4 Véase Tesis 1a. CDXX/2014 (10a.), Gaceta del Semanario Judicial de la Federación, Décima Época, t. I, diciembre de 2014 , p. 233.

5 Véase Tesis 1a. CDXIX/2014 (10a.), Gaceta del Semanario Judicial de la Federación, Décima Época, t. I, diciembre de 2014, p. 234.

6 Ídem. 
3. Contribuye a la formación de la opinión pública sobre asuntos políticos y a la consolidación de un electorado debidamente informado.

Esto es, el ejercicio efectivo del derecho a la libertad de expresión en su dimensión social o política permite la existencia de un gobierno representativo, en el que los ciudadanos participan efectivamente en las decisiones de interés público.

Ahora bien, resulta pertinente señalar que, en el orden jurídico mexicano existe una presunción general de cobertura constitucional de todo discurso expresivo, la cual se explica por la obligación primaria de neutralidad del Estado frente a los contenidos de las opiniones $\mathrm{y}$, en consecuencia, por la necesidad de garantizar que, en principio, no existan personas, grupos, ideas o medios de expresión excluidos a priori del debate público. ${ }^{7}$

Sin embargo, la libertad de expresión al ser un derecho fundamental, como tal, es inalienable e inherente a todas las personas. Por esta razón, el mismo no es un derecho absoluto, puesto que está sujeto a la responsabilidad derivada por contenidos en los que se pone en riesgo valores de la máxima importancia como el interés superior del menor; la afectación a la paz social; el derecho a la vida, la libertad o integridad de las personas, por mencionar algunos. ${ }^{8}$

Por lo que se refiere al ámbito internacional, el derecho fundamental de la libertad de expresión se encuentra reconocido en un amplia gama de instrumentos, entre ellos, la Declaración Universal de los Derechos Humanos, el Pacto Internacional de Derechos Civiles y Políticos y la Convención Americana sobre Derechos Humanos.

El artículo 19 de la Declaración Universal de los Derechos Humanos establece que todo individuo tiene el derecho de mantener opiniones, de investigar y recibir informaciones y opiniones de todo tipo, así como el de difundirlas, sin limitación de fronteras, por cualquier medio de expresión.

Los artículos 19 párrafo 2, del Pacto Internacional de Derechos Civiles y Políticos y 13 párrafo 1, de la Convención Americana sobre Derechos Humanos, disposiciones integradas al orden jurídico nacional en términos de lo previsto por los artículos 10. y 133 de la Constitución Federal, reconocen el derecho fundamental a la libertad de expresión e información, así como el deber del Estado de garantizarla.

En efecto, el artículo 13 de la Convención Americana sobre Derechos Humanos establece que la libertad de pensamiento y expresión abarca la libertad de buscar, recibir y difundir información e ideas de toda índole.

De ahí que, la Corte Interamericana de Derechos Humanos, afirmó que la libertad de expresión tiene una doble dimensión, una individual y una social o colectiva en los términos siguientes:

Sobre la primera dimensión del derecho consagrado en el artículo mencionado, la individual, la libertad de expresión no se agota en el reconocimiento teórico del derecho a hablar o escribir, sino que comprende además, inseparablemente, el derecho a utilizar cualquier medio apropiado para difundir el pensamiento y hacerlo llegar al mayor número de destinatarios. En este sentido, la expresión y la difusión del pensamiento y de la información son indivisibles, de modo que una

\footnotetext{
7 Véase Tesis 1a. XXIX/2011 (10a.), Semanario Judicial de la Federación y su Gaceta, Décima Época, t. 3, enero de 2012, p. 2913.

${ }^{8}$ Véase Jurisprudencia P./J. 26/2007, Semanario Judicial de la Federación y su Gaceta, Novena Época, t. XXV, mayo de 2007, p. 1523.
} 
restricción de las posibilidades de divulgación representa directamente, y en la misma medida, un límite al derecho de expresarse libremente.

Con respecto a la segunda dimensión del derecho consagrado en el artículo 13 de la Convención, la social, es menester señalar que la libertad de expresión es un medio para el intercambio de ideas e informaciones entre las personas; comprende su derecho a tratar de comunicar a otras sus puntos de vista, pero implica también el derecho de todas a conocer opiniones, relatos y noticias. Para el ciudadano común tiene tanta importancia el conocimiento de la opinión ajena o de la información de que disponen otros como el derecho a difundir la propia.

La Corte considera que ambas dimensiones poseen igual importancia y deben ser garantizadas en forma simultánea para dar efectividad total al derecho a la libertad de pensamiento y de expresión en los términos previstos por el artículo 13 de la Convención. [...].9

Asimismo, citando el precedente de la Corte Interamericana de Derechos Humanos en el caso Herrera Ulloa, la Suprema Corte de Justicia de la Nación, señaló que la libertad de expresión:

Se trata de una libertad que tiene tanto una dimensión individual como una dimensión social, y exige no sólo que los individuos no vean impedida la posibilidad de manifestarse libremente, sino también que se respete su derecho como miembros de un colectivo a recibir información y a conocer la expresión del pensamiento ajeno. Así, tener plena libertad para expresar, recolectar, difundir y publicar informaciones e ideas es imprescindible no solamente como instancia esencial de autoexpresión y desarrollo individual, sino como condición para ejercer plenamente otros derechos fundamentales -el de asociarse y reunirse pacíficamente con cualquier objeto lícito, el derecho de petición o el derecho a votar y ser votado- y como elemento determinante de la calidad de la vida democrática en un país, pues si los ciudadanos no tienen plena seguridad de que el derecho los protege en su posibilidad de expresar y publicar libremente ideas y hechos, será imposible avanzar en la obtención de un cuerpo extenso de ciudadanos activos, críticos, comprometidos con los asuntos públicos, atentos al comportamiento y a las decisiones de los gobernantes, capaces de cumplir la función que les corresponde en un régimen democrático. ${ }^{10}$

En concordancia con lo anterior, la Corte Interamericana de Derechos Humanos, estableció la importancia de la libertad de expresión para la democracia, puesto que argumentó que sin una efectiva libertad de expresión, materializada en todos sus términos, la democracia se desvanece, el pluralismo y la tolerancia empiezan a quebrantarse, los mecanismos de control y denuncia ciudadana se empiezan a tornar inoperantes y, en definitiva, se empieza a crear el campo fértil para que sistemas autoritarios se arraiguen en la sociedad. ${ }^{11}$

El Comité para la Eliminación de la Discriminación Racial, respecto de la Libertad de Expresión, estableció que:

\footnotetext{
${ }^{9}$ Corte Interamericana de Derechos Humanos, Caso "La Última Tentación de Cristo" (Olmedo Bustos y otros) Vs. Chile. Fondo, Reparaciones y Costas, Sentencia de 5 de febrero de 2001, Serie C No. 73, párrafos 65, 66 y 67 .

${ }^{10}$ Tesis 1a. CCXV/2009, Semanario Judicial de la Federación y su Gaceta, Novena Época, t. XXX, diciembre de 2009, p. 287.

${ }^{11}$ Véase Corte Interamericana de Derechos Humanos, Op. Cit., nota 9, párrafo 116. Cfr. Corte Interamericana de Derechos Humanos, Caso Vélez Restrepo y Familiares Vs. Colombia, Excepción Preliminar, Fondo, Reparaciones y Costas, Sentencia de 3 de septiembre de 2012, Serie C No. 248, párrafo 141.
} 
es indispensable para la articulación de los derechos humanos y la difusión de conocimientos sobre la situación del disfrute de los derechos civiles, políticos, económicos, sociales y culturales, ayuda a los grupos vulnerables a restablecer el equilibrio de poder entre los componentes de la sociedad, promueve la comprensión y la tolerancia entre las culturas, favorece la deconstrucción de estereotipos raciales, facilita el libre intercambio de ideas y permite contar con opiniones distintas y contraargumentos. ${ }^{12}$

En esa línea argumentativa, el Comité de Derechos Humanos estableció que la libertad de expresión es una condición necesaria para el logro de los principios de transparencia y rendición de cuentas que, a su vez, son esenciales para la promoción y la protección de los derechos humanos. ${ }^{13}$

Además, dicho Comité señaló que la libertad de expresión constituye la base para el pleno goce de una amplia gama de otros derechos humanos. Por ejemplo, la libertad de expresión es fundamental para el disfrute de los derechos a la libertad de reunión y de asociación, y para el ejercicio del derecho de voto. ${ }^{14}$

Ahora bien, el artículo 13 de la citada Convención Americana en su párrafo 2, establece que el ejercicio de la libertad de expresión no puede estar sujeto a previa censura sino a responsabilidades ulteriores, las que deben estar expresamente fijadas por la ley y ser necesarias para asegurar: el respeto a los derechos o a la reputación de los demás, o la protección de la seguridad nacional, el orden público, la salud o la moral públicas.

Del artículo invocado se observa que la regla es la libertad y la excepción son las restricciones o límites a esa libertad, al señalar el respeto a los derechos o la reputación de las demás personas, o la protección a la seguridad nacional, el orden público, la salud o la moral pública.

En este contexto, es importante establecer que la censura previa se concibe como una interferencia o presión directa o indirecta sobre cualquier expresión, opinión o información difundida a través de cualquier medio de comunicación, la cual, a nivel convencional, está prohibida, en tanto limita la circulación libre de ideas y opiniones, permite la imposición arbitraria de aquéllas y la creación de obstáculos al libre flujo informativo, de suerte que no se justifica su imposición.

Esto es, el Sistema Interamericano de Derechos Humanos presume que todas las formas de expresión, independientemente de su contenido, se encuentran protegidas por el artículo 13 de la multireferida Convención. Sin embargo, por disposición expresa del instrumento internacional en comento, escapan de dicha cobertura de protección: ${ }^{15}$

Toda propaganda a favor de la guerra;

\footnotetext{
${ }^{12}$ Comité para la Eliminación de la Discriminación Racial, Observación: CERD-GC-35 La lucha contra el discurso de odio racista, párrafo 29.

${ }^{13}$ Véase Comité de Derechos Humanos, Observación: CCPR-GC-34 Libertad de opinión y expresión (Sustituye la CCPR/GC/10), párrafo 3 .

${ }^{14}$ Ibídem, párrafo 4.

${ }^{15}$ Véase Tesis 1a. CDXXI/2014 (10a.), Gaceta del Semanario Judicial de la Federación, Décima Época, t. I, diciembre de 2014, p. 237.
} 
Toda apología del odio nacional, racial o religioso que inciten a la violencia o cualquier otra acción delictiva similar contra cualquier persona o grupo de personas, por ningún motivo.

En ese sentido, los tratados de derechos humanos, integrados al orden jurídico nacional, conciben de manera homogénea que el derecho a la libertad de expresión encuentra sus límites en el pleno goce de otras libertades, con las que se relacionan.

Al mismo tiempo, en concordancia con el Sistema Interamericano de Derechos Humanos, la Constitución Política de los Estados Unidos Mexicanos establece, como quedó señalado en supra líneas, que deben entenderse protegidas todas las formas de expresión, y solamente puede entenderse derrotada dicha presunción bajo razones imperiosas.

Una vez establecido lo anterior, es pertinente señalar que el avance de la modernidad y las tecnologías, implicaron que el Estado Mexicano hiciera frente a las nuevas realidades que surgieron, entre ellas la Internet.

Así pues, el 11 de junio de 2013 el artículo 6o. de la Constitución Política de los Estados Unidos Mexicanos sufrió una reforma, para establecer como mandato para el Estado, garantizar el derecho de acceso a las tecnologías de la información y comunicación, así como los servicios de radiodifusión y telecomunicaciones, incluido el de banda ancha e Internet.

Otro claro ejemplo de lo anterior, es que en el dictamen de la Comisión de Puntos Constitucionales de la Cámara de Senadores relativo a la reforma en materia de telecomunicaciones, se precisaron, entre otras, las siguientes razones para incluir en el catálogo de derechos fundamentales el acceso a la Internet:

La Internet se ha consolidado como la herramienta de comunicación e interconexión del siglo XXI $y$ ha expandido el terreno para la diversidad, la tolerancia y el ejercicio pleno de los derechos humanos, en particular el derecho a la libertad de expresión y el acceso a la información. ${ }^{16}$

La reforma tiene como objeto garantizar la libertad de expresión y de difusión, y el derecho a la información.17

La Internet constituye una herramienta básica para el desarrollo personal y profesional de estudiantes y de la sociedad de cualquier país. El acceso a Internet es un derecho fundamental por su importancia en cuanto a la libertad de prensa, de pensamiento, de expresión, desarrollo de la personalidad y libre consciencia se refiere. 18

Por consiguiente, se advierte con meridiana claridad que la inclusión en la Carta Magna del acceso a Internet como un verdadero derecho fundamental, se centró en potencializar los derechos fundamentales de libertad de expresión y acceso a la información.

\section{LA INTERNET Y LAS REDES SOCIALES}

El avance de las tecnologías y el surgimiento de la Internet han generado la aparición de nuevos escenarios para el ejercicio de la libertad de expresión, como lo son las redes socia-

\footnotetext{
${ }^{16}$ Sala Regional Especializada del Tribunal Electoral del Poder Judicial de la Federación, SRE-PSC-8/2016, Promoventes: Miguel Ángel Rodríguez Llamas y J. Ramón Flores Reyes, 27 de enero de 2016, p. 64.

${ }^{17}$ Sala Regional Especializada del Tribunal Electoral del Poder Judicial de la Federación, SRE-PSC-11/2016, Denunciantes: MORENA y Otros, 17 de febrero de 2016, p. 34.

${ }^{18}$ Sala Regional Especializada del Tribunal Electoral del Poder Judicial de la Federación, SRE-PSC-268/2015, Promovente: Partido Revolucionario Institucional, 26 de noviembre de 2015, p. 17 y 18.
} 
les. Esas nuevas herramientas han generado a los usuarios una comunicación instantánea, rápida, efectiva y gratuita.

La Sala Superior del Tribunal Electoral del Poder Judicial de la Federación estableció que la Internet es, en esencia, un medio de comunicación global que permite contactar personas, instituciones, corporaciones, gobiernos, etcétera, alrededor de muchas partes del mundo. ${ }^{19}$

Señala que no es una entidad física o tangible, sin embargo, aun con su característica incorpórea se encuentra al alcance de todas aquellas personas que cuenten con los medios para su conexión remota, de modo que es una vasta red que interconecta innumerables grupos de redes más pequeñas, erigiéndose como una especie de red de redes. ${ }^{20}$

Que actualmente, no se tiene dato que permita asegurar con certeza que exista un banco de datos centralizado que comprenda todo el contenido que puede obtenerse a través de Internet. De manera que, la característica de universalidad que posee la Internet es lo que dificulta una regulación y control específicos del contenido de los materiales que quedan a disposición de los usuarios de dicho medio de comunicación. ${ }^{21}$

En esencia, La Internet es un instrumento de telecomunicación que tiene por objeto la transmisión electrónica de información a través de un espacio virtual denominado ciberespacio; que constituye una vía idónea y útil para enviar elementos informativos a la sociedad. $^{22}$

En efecto, la Internet, es una herramienta para que cualquier persona pueda difundir y acceder a información de su interés, y que su utilización ha permitido una descentralización extrema de la información, que debido a su rápida masificación en el espacio virtual, corre el riesgo de que se reproduzca, sin saberse con certeza cuál fue su fuente de origen, especialmente tratándose de redes sociales, en las que sus usuarios intercambian información y contenidos (textos, imágenes, archivos, links a otras páginas, entre otros) de modo que crean una comunidad de usuarios virtual e interactiva, esto es, crean un foro de comunicación en el que participa una colectividad indefinida de personas, aportando o difundiendo documentos e información. ${ }^{23}$

Además, en virtud de la característica global de la Internet, dicho medio no tiene una limitante o restricción en cuanto a la forma en que se presenta la información y contenido, ni mucho menos, hay un control efectivo respecto de que lo difundido realmente emane de la conducta de su autor o si ha sido producto de una alteración por terceras personas, dada la cantidad de avances tecnológicos que permiten hacer manipulaciones, ajenas a la realidad, de ahí que la información contenida en la misma no debe considerarse absoluta, salvo casos muy específicos que permiten la comprobación o respaldo de lo que se informa. ${ }^{24}$

En ese orden de ideas, la aparición de la herramienta novedosa de la Internet visto desde la perspectiva del ejercicio de la libertad de expresión, ha generado que diferentes organismos comiencen a deliberar respecto de su uso. Tal es el caso del Consejo de Derechos Humanos de las Naciones Unidas, quien el 29 de junio de 2012, determinó que los derechos de las per-

\footnotetext{
19 Véase http://portal.te.gob.mx/colecciones/sentencias/html/SUP/2009/RAP/SUP-RAP-oo153-2009.htm. $1^{\circ}$ de marzo de 2016.

${ }^{20}$ Ídem.

${ }^{21}$ Ídem.

${ }^{22}$ Ídem.

${ }^{23}$ Véase http://portal.te.gob.mx/colecciones/sentencias/html/SUP/2014/JDC/SUP-JDC-oo401-2014.htm. $1^{\circ}$ de marzo de 2016.

24 Véase http://portal.te.gob.mx/colecciones/sentencias/html/SUP/2012/RAP/SUP-RAP-oo268-2012.htm. $1^{\circ}$ de marzo de 2016.
} 
sonas también deben estar protegidos en Internet, en particular la libertad de expresión, el cual es aplicable sin consideración de fronteras.

Asimismo, el Comité de Derechos Humanos de las Naciones Unidas estableció que los Estados parte, deberían tener en cuenta la medida que la evolución de las tecnologías de la información y la comunicación, como Internet y los sistemas de difusión electrónica de la información en tecnología móvil, han cambiado sustancialmente las prácticas de la comunicación en todo el mundo. Ahora, existe una red mundial que intercambia ideas y opiniones, que no se basa necesariamente en la intermediación de los medios de comunicación de masas. Los Estados partes deberían tomar todas las medidas necesarias para fomentar la independencia de esos nuevos medios y asegurar el acceso a los mismos de los particulares. ${ }^{25}$

Por su parte, el Consejo de Derechos Humanos de la Organización de las Naciones Unidas, el 12 de septiembre de 2011 emitió la observación general 34, sobre el artículo 19 del Pacto Internacional de Derechos Civiles y Políticos en la que estableció lo siguiente: ${ }^{26}$

- La libertad de expresión es una condición necesaria para el logro de los principios de transparencia y rendición de cuentas que, a su vez, son esenciales para la promoción y la protección de los derechos humanos."

- Los Estados parte deberían tomar todas las medidas necesarias para fomentar la independencia de los nuevos medios de comunicación como Internet y asegurar el acceso a los mismos.

- Toda limitación al funcionamiento de los sitios web, los blogs u otros sistemas de difusión de información en Internet, solo será admisible en la medida en que sea compatible con el derecho de libertad de expresión.

- Las restricciones permisibles se deben referir en general a un contenido concreto; las prohibiciones genéricas del funcionamiento de ciertos sitios y sistemas no son compatibles con la libertad de expresión.

- Tampoco es compatible con la libertad de expresión, prohibir que un sitio o un sistema de difusión de la información publique material por el mero hecho de que ese material pueda contener críticas al gobierno o al sistema político al que este se adhiere.

Por su parte, la Declaración Conjunta sobre la Libertad de Expresión e Internet señala que la neutralidad de la red, es un principio que persigue la libertad de acceso y elección de los usuarios de utilizar, enviar, recibir u ofrecer cualquier contenido, aplicación o servicio legal por medio de Internet, de tal forma que no esté condicionada, direccionada o restringida, por medio de bloqueo, filtración o interferencia. Tal principio se traduce en una condición

${ }^{25}$ Comité de Derechos Humanos, Observación: CCPR-GC-34 Libertad de opinión y expresión (Sustituye la CCPR/GC/10), párrafo 15.

${ }^{26}$ Véase. Sala Regional Especializada del Tribunal Electoral del Poder Judicial de la Federación, Op. Cit., nota 16, p. 76

CIENCIA JURÍdICA. Departamento de Derecho. División de Derecho, Política y Gobierno, Universidad de Guanajuato - Año 5, No. 10 , 2016 
necesaria para ejercer la libertad de expresión en Internet, en términos del artículo 13 de la Convención Americana sobre Derechos Humanos.

Inclusive, la Sala Superior del Tribunal Electoral del Poder Judicial de la Federación argumentó que la Internet es un medio que influye en el ánimo público, en la formación de opinión y lo hace cada vez con mayor alcance y penetración conforme se expande, en México y el mundo, la llamada sociedad de la información. Sin embargo, es menester subrayar también, que su naturaleza y su régimen legal es muy distinto al de otros medios de comunicación masiva, tales como la prensa escrita o los canales abiertos de radio y televisión, lo que provoca incluso, que el Código Electoral omita cualquier intención regulatoria. ${ }^{27}$

Asimismo, Sala en comento, citando al profesor Lawrence Lessig, abogado y constitucionalista de la Universidad de Stanford, especializado en derecho informático, señaló que un diario o una televisora, son medios ubicados espacialmente en un país, una ciudad, un municipio, situados en una región geográfica, pero Internet es una red internacional cuya regulación ha de tener ese carácter o no será. Su naturaleza descentralizada propicia la colocación de materiales desde casi cualquier parte del mundo y el derecho se encuentra claramente rezagado pues sigue sin reconocer a especificidad y singularidad de la red. No es casual entonces, que el IFE y la ley electoral mexicana, no contemplen definiciones ni instrumentos para regular lo que ocurre en la Internet, pues se trata de un debate mundial todavía no resuelto. ${ }^{28}$

En ese sentido, se advierte con meridiana claridad que la Internet representa un medio de comunicación que posee algunas diferencias sustanciales o trascendentales con la radio y televisión, la principal es la señalada por la multireferida Sala Superior, consistente en la especial voluntad que en última instancia se requiere para acceder o recibir determinada información.

Para ingresar a los contenidos que se encuentra en Internet, es necesario un acto volitivo que resulta del ánimo de cada persona para acceder a páginas y sitios de su particular interés, las redes sociales por ejemplo, por lo que se considera que cada usuario de la web ejerce de forma libre visitar diversas direcciones de su elección, así pues se puede afirmar que dicho medio de comunicación tiene como característica fundamental el ser pasivo. ${ }^{29}$

Lo anterior, a diferencia de la información transmitida en radio y/o televisión, en los cuales los sujetos receptores carecen de la facultad de decisión respecto de lo que en ellos se difunde, en otras palabras carecen de la facultad de decidir qué información y contenidos desean consultar.

En esa tesitura, lo que fundamenta de manera trascendental el criterio sostenido por la Sala en comento, es que la diferencia entre la Internet y el resto de los medios de comunicación como la televisión y la radio, consiste en que el acto de voluntad requiere de una especial consciencia del interesado y ejecución deliberada de buscar una información en particular.

Esto es, en términos generales en la Internet, a diferencia de lo que ocurre en la televisión o la radio, para acceder a determinados contenidos publicados en una página general o en alguna red social, se debe ingresar, de forma exacta, la dirección electrónica de la página [de internet o de la persona en la red social] que desea visitar o, en su defecto, apoyarse en

\footnotetext{
${ }^{27}$ Véase Sala Superior del Tribunal Electoral del Poder Judicial de la Federación, Op. Cit, nota 19.

${ }^{28}$ Ibídem. Citando a Lessig, Lawrence. Código, y otras leyes del ciberespacio, Taurus, Madrid, (2001).

29 Véase Op. Cit, nota 19. Véase. Op. Cit, nota 23. 
buscadores a fin de que en base a aproximaciones, se realice la exploración y se muestre una lista de direcciones con los temas relacionados..$^{30}$

Por lo anterior, la multireferida instancia jurisdiccional federal ha reconocido, expresamente, que en especial las redes sociales son un medio de comunicación de carácter pasivo, en virtud de que además, de que debe existir la voluntad de buscar cierta información o contenido, para consultar la misma a través de algún perfil de un usuario, es necesario tomar la determinación adicional de formar parte de dicha red social..$^{31}$

En esa tesitura, la información y contenido de las redes sociales no tiene una difusión indiscriminada o automática, al tratarse de un medio de comunicación de carácter pasivo, ya que para tener acceso a la información y contenidos en dichas redes sociales se requiere el despliegue y realización de ciertos actos, en los cuales es imprescindible la intención previa de acceder a dichos contenidos y además formar parte de dicha red social, puesto que en el uso ordinario las redes sociales no permiten accesos espontáneos. ${ }^{32}$

Cabe destacar que, en virtud de las características en general de la Internet y en específico de las redes sociales, ${ }^{33}$ la Sala Especializada del Tribunal Electoral del Poder Judicial de la Federación, arribó a la conclusión de considerar que las redes sociales son espacios de plena libertad, las cuales se han convertido en herramientas idóneas para lograr una sociedad mayor y mejor informada; consciente en la toma de decisiones públicas que trascienden al mejoramiento de la calidad de vida del pueblo; las cuales facilitan la libertad de expresión y de asociación; permiten compartir el conocimiento y el aprendizaje; y potenciar la colaboración entre personas, aspectos que fortalecen a la democracia.. ${ }^{34}$

\section{LA LIBERTAD DE EXPRESIÓN EN EL CONTEXTO DE LOS PROCESOS ELECTORALES}

El derecho fundamental de libertad de expresión adquiere una protección especial en el contexto de los procesos electorales. Ello, en virtud de que es condición sine qua non para el desarrollo del debate público abierto y vigoroso, como elemento indispensable de un sistema democrático, para la deliberación y ejercicio informado de los derechos político-electorales; y por ende para la consolidación, el funcionamiento y la preservación de la democracia.

En efecto, la libertad de expresión siempre debe tener la protección más amplia, pero sobre todo, en el contexto del desarrollo de los procesos electorales, porque se erige en con-

\footnotetext{
${ }^{30}$ Véase Sala Superior del Tribunal Electoral del Poder Judicial de la Federación, SUP-JRC-71/2015, Actor: Partido Acción Nacional, 24 de noviembre de 2014, p. 48.

${ }^{31}$ Véase Ibídem, p. 46.

${ }^{32}$ Véase Ibídem, p. 45 y 46.

${ }^{33}$ Las redes sociales son medios de comunicación global que permiten una descentralización extrema de la información a través de su rápida masificación en el espacio virtual, lo que permite contactar personas, instituciones, corporaciones, gobiernos, alrededor de muchas partes del mundo. Por lo que poseen una actuación activa.

${ }^{34}$ Véase Sala Regional Especializada del Tribunal Electoral del Poder Judicial de la Federación, SRE-PSD-2/2016, Denunciante: Partido Revolucionario Institucional, 27 de enero de 2016, p. 24

Véase Sala Regional Especializada del Tribunal Electoral del Poder Judicial de la Federación, SRE-PSD-8/2016, Promoventes: Miguel Ángel Rodríguez Llamas y J. Ramón Flores Reyes, 27 de enero de 2016, p. 60.

Véase Sala Regional Especializada del Tribunal Electoral del Poder Judicial de la Federación, SREPSC-11/2016, Denunciantes: MORENA y Otros, 17 de febrero de 2016, p. 43.

Véase Sala Regional Especializada del Tribunal Electoral del Poder Judicial de la Federación, SRE-PSD-16/2016, Denunciante: Partido Revolucionario Institucional, 4 de febrero de 2016, p. 16.

Véase Sala Regional Especializada del Tribunal Electoral del Poder Judicial de la Federación, SREPSC-268/2015, Promovente: Partido Revolucionario Institucional, 26 de noviembre de 2015, p. 35.
} 
dición necesaria para el intercambio de ideas, la posibilidad de un debate vigoroso entre los participantes y, de manera preponderante, la formación de un electorado informado y consciente, al momento de la emisión del sufragio; en suma, para el fortalecimiento y ejercicio pleno del sistema democrático.

La Suprema Corte de Justicia de la Nación ha señalado que el debate en temas de interés público debe ser desinhibido, robusto y abierto, pudiendo incluir ataques vehementes, cáusticos y desagradablemente mordaces sobre personajes públicos o, en general, ideas que puedan ser recibidas desfavorablemente por sus destinatarios y la opinión pública, de modo que no sólo se encuentran protegidas las ideas que son recibidas favorablemente o las que son vistas como inofensivas o indiferentes. Estas son las demandas de una sociedad plural, tolerante y abierta, sin la cual no existe una verdadera democracia. ${ }^{35}$

Así las cosas, en el contexto de un proceso electoral la libertad de expresión, en la mayoría de los casos, se constituye en su dimensión política o social, esto es, en una institución ligada de manera inescindible al pluralismo político, valor esencial del Estado democrático. ${ }^{36}$

En este sentido, en el contexto de un proceso electoral la libertad de expresión cumple numerosas funciones, entre otras, mantiene abiertos los canales para el disenso y el cambio político; y se configura como un contrapeso al ejercicio del poder, ya que contribuye a la formación de la opinión pública sobre asuntos políticos y a la consolidación de un electorado debidamente informado, ${ }^{37}$ de manera que debe garantizarse y maximizarse su protección. ${ }^{38}$

Así, por ejemplo, encontramos que la Suprema Corte de Justicia de la Nación ha reconocido que las expresiones e información atinentes a los candidatos a ocupar cargos públicos, gozan de una mayor protección. Ello, en virtud de que la naturaleza de las funciones públicas que cumplen, configuran un tipo diferente de protección de su reputación o de su honra frente a las demás personas, por lo que correlativamente deben tener un umbral mayor de tolerancia ante la crítica, máxime en el debate público que se origina en los procesos electorales, puesto que la circulación de dichos contenidos, permitirá que los ciudadanos puedan ejercer su voto de manera responsable e informada. ${ }^{39}$

\section{CONCLUSIONES}

La libertad de expresión, como derecho fundamental, adquiere especial relevancia en el contexto de los procesos electorales. Puesto que permite al ciudadano una participación más proactiva en la vida pública, más allá de la mera emisión del sufragio y genera una serie de

\footnotetext{
${ }^{35}$ Véase Jurisprudencia: 1a./J. 32/2013 (10a.), Semanario Judicial de la Federación y su Gaceta, Décima Época, t. 1, abril de 2013, p. 540.

${ }^{36}$ Véase Op. Cit, nota 5.

${ }^{37}$ Ídem.

${ }^{38}$ Existen numerosos criterios sustentados por la Corte Interamericana de Derechos Humanos relacionados con la libertad de expresión que denotan su maximización, al respecto pueden consultarse las resoluciones de los casos: "La Última Tentación de Cristo" (Olmedo Bustos y otros) Vs. Chile. Sentencia de 5 de febrero de 2001; Caso Herrera Ulloa Vs. Costa Rica. Sentencia de 2 de julio de 2004; Ivcher Bronstein Vs. Perú. Sentencia de 6 de febrero de 2001; Ríos y otros Vs. Venezuela. Sentencia de 28 de enero de 2009; Ricardo Canese Vs. Paraguay. Sentencia de 31 de agosto de 2004; Palamara Iribarne Vs. Chile. Sentencia de 22 de noviembre de 2005; Claude Reyes y otros Vs. Chile. Sentencia de 19 de septiembre de 2006; Kimel Vs. Argentina. Sentencia de 2 de mayo de 2008; Tristán Donoso Vs. Panamá. Sentencia de 27 de enero de 2009; y Fontevecchia y D'Amico Vs. Argentina. Sentencia de 29 de noviembre de 2011.

39 Véase Tesis 1a. CLII/2014 (10a.), Gaceta del Semanario Judicial de la Federación, Décima Época, t. I, abril de 2014, p. 806
} 
retos a las reglas de la contienda electoral que, cada vez busca una mayor regulación de la participación de instituciones, entidades públicas, privadas, partidos políticos y ciudadanos en la materia de mérito.

De hecho, la protección de la libertad en comento, representa una conditio sine qua non para la vida democrática de una sociedad que busca alcanzar la democracia sustantiva y la construcción de ciudadanía, máxime cuando la sociedad se ve impactada por el uso de la Internet y las redes sociales, estas últimas, herramientas eficaces para la comunicación y para la masificación de la información, que hacen necesaria su protección progresiva, lejos del afán sobre regulatorio y restrictivo que, en ámbitos como la radio y televisión, caracteriza a la materia electoral.

Además, la libertad de expresión materializada en las redes sociales, representa, más allá de una tarea pendiente para el legislador o un interesante reto para el ejercicio de la función jurisdiccional, la invaluable oportunidad que tiene el ciudadano de contar con múltiples opciones informativas, que coadyuven en su formación cívica a partir del contraste de datos e ideas sobre la trayectoria, perfil y propuestas de los candidatos. Datos que no sólo son generados y difundidos por el candidato, el partido que lo postula, su respectivo equipo de campaña o contrincante sino de todo aquel ciudadano que estima poseer información útil que permita conocer, de mejor manera, a los diferentes actores de la contienda electoral.

Asimismo, el vacío legal que existe respecto de la regulación de la multireferida libertad de expresión, representa una oportunidad para el Estado mexicano. Toda vez que, lejos de reglamentar y limitar, debe pugnar por maximizar y potencializar el referido derecho fundamental, en aras de consolidar un electorado informado y consciente, al momento de la emisión del sufragio; y con esto, lograr el fortalecimiento y ejercicio pleno del sistema democrático y de los derechos político-electorales de los ciudadanos.

De ahí que, mientras se crea la hipótesis normativa regulatoria garante del derecho fundamental que nos ocupa, las autoridades jurisdiccionales solamente podrán limitar y reglamentar la libertad de expresión ejercida en los procesos electorales a través de la internet, específicamente en las redes sociales, en circunstancias determinadas, cuando se trate de contenidos y expresiones a favor de la guerra; odio nacional, racial o religioso que inciten a la violencia o cualquier otra acción delictiva similar contra cualquier persona o grupo de personas. $\mathrm{O}$ en su caso, en determinadas circunstancias, cuando vayan en contra de los derechos o la reputación de las demás personas, o de la protección a la seguridad nacional, del orden público, de la salud o de la moral pública.

\section{FUENTES}

Comité de Derechos Humanos, Observación: CCPR-GC-34 Libertad de opinión y expresión (Sustituye la CCPR/GC/10).

Comité para la Eliminación de la Discriminación Racial, Observación: CERD-GC-35 La lucha contra el discurso de odio racista, párrafo 29.

Constitución Política de los Estados Unidos Mexicanos

Convención Americana sobre Derechos Humanos 
Corte Interamericana de Derechos Humanos, Caso "La Última Tentación de Cristo" (Olmedo Bustos y otros) Vs. Chile. Fondo, Reparaciones y Costas, Sentencia de 5 de febrero de 2001, Serie C No. 73, párrafos 65, 66 y 67.

Corte Interamericana de Derechos Humanos, Caso Vélez Restrepo y Familiares Vs. Colombia, Excepción Preliminar, Fondo, Reparaciones y Costas, Sentencia de 3 de septiembre de 2012, Serie C No. 248, párrafo 141.

Declaración Universal de los Derechos Humanos

Jurisprudencia P./J. 26/2007, Semanario Judicial de la Federación y su Gaceta, Novena Época, t. XXV, mayo de 2007, p. 1523.

Jurisprudencia P./J. 25/2007, Semanario Judicial de la Federación y su Gaceta, Novena Época, t. XXV, mayo de 2007, p. 1520.

Jurisprudencia: 1a./J. 32/2013 (10a.), Semanario Judicial de la Federación y su Gaceta, Décima Época, t. 1, abril de 2013, p. 540.

Pacto Internacional de Derechos Civiles y Políticos

Sala Regional Especializada del Tribunal Electoral del Poder Judicial de la Federación, SREPSC-8/2016, Promoventes: Miguel Ángel Rodríguez Llamas y J. Ramón Flores Reyes, 27 de enero de 2016, p. 64.

Sala Regional Especializada del Tribunal Electoral del Poder Judicial de la Federación, SREPSC-11/2016, Denunciantes: MORENA y Otros, 17 de febrero de 2016, p. 34.

Sala Regional Especializada del Tribunal Electoral del Poder Judicial de la Federación, SREPSC-268/2015, Promovente: Partido Revolucionario Institucional, 26 de noviembre de 2015, p. 17 y 18.

Sala Regional Especializada del Tribunal Electoral del Poder Judicial de la Federación, SREPSD-2/2016, Denunciante: Partido Revolucionario Institucional, 27 de enero de 2016, p. 24 .

Sala Regional Especializada del Tribunal Electoral del Poder Judicial de la Federación, SREPSD-8/2016, Promoventes: Miguel Ángel Rodríguez Llamas y J. Ramón Flores Reyes, 27 de enero de 2016, p. 60.

Sala Regional Especializada del Tribunal Electoral del Poder Judicial de la Federación, SREPSC-11/2016, Denunciantes: MORENA y Otros, 17 de febrero de 2016, p. 43.

Sala Regional Especializada del Tribunal Electoral del Poder Judicial de la Federación, SREPSD-16/2016, Denunciante: Partido Revolucionario Institucional, 4 de febrero de 2016, p. 16.

Sala Regional Especializada del Tribunal Electoral del Poder Judicial de la Federación, SREPSC-268/2015, Promovente: Partido Revolucionario Institucional, 26 de noviembre de 2015, p. 35.

Sala Superior del Tribunal Electoral del Poder Judicial de la Federación, http://portal.te.gob. $\mathrm{mx} /$ colecciones/sentencias/html/SUP/2009/RAP/SUP-RAP-00153-2009.htm. Fecha de consulta: $1^{\circ}$ de marzo de 2016. 
Sala Superior del Tribunal Electoral del Poder Judicial de la Federación, http://portal.te.gob. $\mathrm{mx} /$ colecciones/sentencias/html/SUP/2014/JDC/SUP-JDC-00401-2014.htm. Fecha de consulta: $1^{\circ}$ de marzo de 2016.

Sala Superior del Tribunal Electoral del Poder Judicial de la Federación, http://portal.te.gob. $\mathrm{mx} /$ colecciones/sentencias/html/SUP/2012/RAP/SUP-RAP-00268-2012.htm. Fecha de consulta: $1^{\circ}$ de marzo de 2016.

Sala Superior del Tribunal Electoral del Poder Judicial de la Federación, SUP-JRC-71/2015, Actor: Partido Acción Nacional, 24 de noviembre de 2014, p. 48.

Tesis 1a. CCXV/2009, Semanario Judicial de la Federación y su Gaceta, Novena Época, t. XXX, diciembre de 2009, p. 287.

Tesis 1a. CDXIX/2014 (10a.), Gaceta del Semanario Judicial de la Federación, Décima Época, t. I, diciembre de 2014, p. 234.

Tesis 1a. CDXVIII/2014 (10a.), Gaceta del Semanario Judicial de la Federación, Décima Época, t. I, diciembre de 2014, p. 236.

Tesis 1a. CDXX/2014 (10a.), Gaceta del Semanario Judicial de la Federación, Décima Época, t. I, diciembre de 2014, p. 233.

Tesis 1a. CDXX/2014 (10a.), Semanario Judicial de la Federación, Décima Época, t. I, diciembre de 2014, p. 233.

Tesis 1a. CDXXI/2014 (10a.), Gaceta del Semanario Judicial de la Federación, Décima Época, t. I, diciembre de 2014, p. 237.

Tesis 1a. CLII/2014 (10a.), Gaceta del Semanario Judicial de la Federación, Décima Época, t. I, abril de 2014, p. 806.

Tesis 1a. XXIX/2011 (10a.), Semanario Judicial de la Federación y su Gaceta, Décima Época, t. 3, enero de 2012, p. 2913.

Tesis 1a. XXX/2016 (10a.), Semanario Judicial de la Federación, Décima Época, febrero de 2016, publicación semanal. 